\title{
0810 SCOPE AND PATTERNS OF INTERPERSONAL VIOLENCE IN EUROPE FIRST RESULTS OF THE EU INJURY DATABASE (IDB)
}

R Bauer*, N Minicuci, R Kisser Correspondence: Austrian Road Safety Board (KfV), Schleiergasse 18, A-1100 Vienna, Austria

\subsection{6/ip.2010.029215.810}

Interpersonal violence is an issue of growing public concern and there is experience that data from emergency departments can substantially broaden the evidence needed to tackle the many forms and different environments that violence occurs in. The EU Injury Database (IDB) is a specially designed large scale injury surveillance systems for all sectors of injury prevention, since 2005 including also interpersonal violence. The IDB is based on a sample of emergency departments in currently $12 \mathrm{EU}$ member states. First results of the IDB violence module have been made available in 2009 (2005-2007 data) providing both basic epidemiological injury patterns (age, sex of the victim, place of occurrence, mechanism, type of injury etc), as well as specific information about the perpetrator (age, sex, relation to victim) for various contexts of assault (violent dispute, illegal acquisition, drug-related incident, sexual 


\section{IP Safety 2010 abstracts}

assault, dang-related incident). From these results also national and EU level estimates for the incidence of violence have been derived: for example, for the EU an overall interpersonal violence rate of one hospital-treated injury per 1000 inhabitants (or 1.8 million people annually), with the majority of injuries related to violent disputes. In the presentation, the quality, validity and plausibility of the IDB estimates for interpersonal violence will be discussed (through comparison with results from other sources like household surveys and study results); as well as conclusions of the Eurosafe violence task force on the potential of the IDB for violence monitoring and recommended improvements will be given. 